\title{
Abatacept is Efficacious in the Treatment of Older Patients with csDMARD-Refractory Rheumatoid Arthritis: A Prospective, Multicenter, Observational Study
}

\author{
Sei Muraoka (D) - Zento Yamada (D) - Mai Kawazoe - Wataru Hirose (D) - Hajime Kono (D) • \\ Shinsuke Yasuda (D) · Yukiko Komano (D) · Hiroshi Kawano (D) Toshihiko Hidaka • \\ Shusaku Nakashima (D) · Tsuyoshi Kasama (D) · Tamio Teramoto $\cdot$ Toshihiro Nanki
}

Received: May 24, 2021 / Accepted: August 2, 2021 / Published online: August 26, 2021

(C) The Author(s) 2021

\section{ABSTRACT}

Introduction: Abatacept efficacy in older patients with rheumatoid arthritis (RA) has been primarily demonstrated via retrospective comparisons with younger patients. The objective of this study was to compare efficacy of

Supplementary Information The online version contains supplementary material available at https://doi. org/10.1007/s40744-021-00356-2.

S. Muraoka · Z. Yamada · M. Kawazoe · T. Nanki ( $ه)$ Division of Rheumatology, Department of Internal Medicine, Toho University School of Medicine, 6-111 Omori-nishi, Ota-ku, Tokyo 143-8541, Japan e-mail: toshihiro.nanki@med.toho-u.ac.jp

W. Hirose

Hirose Clinic of Rheumatology, Saitama, Japan

H. Kono

Department of Internal Medicine, Teikyo University School of Medicine, Tokyo, Japan

S. Yasuda

Department of Rheumatology, Endocrinology and Nephrology, Graduate School of Medicine and Faculty of Medicine, Hokkaido University, Sapporo, Japan

\section{S. Yasuda}

Department of Rheumatology, Tokyo Medical and Dental University, Tokyo, Japan

Y. Komano

Department of Rheumatology, Jujo Takeda

Rehabilitation Hospital, Kyoto, Japan abatacept in older vs. younger patients with RA, and efficacy of abatacept with that of conventional synthetic disease-modifying anti-rheumatic drugs (csDMARDs) in both age groups.

Methods: This prospective, multicenter, observational study (UMIN000014913) enrolled csDMARD-refractory patients without previous biological DMARD treatment. Abatacept (A) or csDMARDs (C) were administered at the treating physician's discretion to older $(\mathrm{O}, \geq 65$ years) and younger $(\mathrm{Y}, 20-64$ years $)$

\section{H. Kawano}

Department of Respiratory Medicine and Rheumatology, Graduate School of Biomedical Sciences, Tokushima University, Tokushima, Japan

T. Hidaka

Institute of Rheumatology, Zenjinkai Miyazaki-

Zenjinkai Hospital, Miyazaki, Japan

\section{S. Nakashima}

Division of Hematology, Rheumatology and Respiratory Medicine, Department of Internal Medicine, Faculty of Medicine, Kagawa University, Takamatsu, Kagawa, Japan

\section{T. Kasama}

Division of Rheumatology, Department of Medicine, Showa University School of Medicine, Tokyo, Japan

T. Teramoto

Teikyo Academic Research Center, Teikyo University School of Medicine, Tokyo, Japan 
patients, producing $\mathrm{AO}, \mathrm{AY}, \mathrm{CO}$, and $\mathrm{CY}$ groups. Clinical efficacy after 24 weeks was evaluated using European League Against Rheumatism (EULAR) erythrocyte sedimentation rate response criteria.

Results: Overall, 202 patients were evaluated. Compared with the CO group, more patients in the AO group achieved a EULAR good or moderate response $(p<0.0001)$. Compared with the $\mathrm{CY}$ group, more patients in the AY group achieved a EULAR good or moderate response $(p<0.01)$. Similar proportions of patients in the $\mathrm{AO}$ and AY groups achieved a EULAR good response or a good or moderate response. Few adverse events were reported.

Conclusions: This prospective study demonstrated that abatacept is efficacious and safe in older patients with RA and a history of being refractory to csDMARDs. Abatacept was shown to be more efficacious than adding or switching to a new csDMARD in both younger and older csDMARD-refractory patients with RA.

Trial Registration: UMIN000014913.

Keywords: Abatacept; Aged; Antirheumatic agents; Prospective studies; Rheumatoid arthritis; Treatment outcome

\section{Key Summary Points}

Why carry out this study?

Half of the older patients with rheumatoid arthritis (RA) do not respond adequately to the current therapeutic agents. A potent and safe treatment option needs to be established especially for older patients.

We prospectively analyzed the efficacy of abatacept in older and younger patients with inadequate response to csDMARD and compared with adding or switching csDMARD.

What was learned from the study?

The efficacies of abatacept are similar in older and younger patients with RA.
Abatacept constitutes an overall more favorable treatment option for older patients as well as younger patients than adding or switching to a new csDMARD treatment.

\section{INTRODUCTION}

Rheumatoid arthritis (RA) is an inflammatory disease that is characterized by synovitis, bone erosion, and cartilage destruction, which ultimately lead to joint destruction [1]. An intensive treatment strategy has been established to achieve disease remission or lower disease activity, thereby reducing bone destruction and restoring physical function [2]. The widespread use of biological disease-modifying anti-rheumatic drugs (bDMARDs) and Janus kinase inhibitors has greatly improved the prognosis of patients with RA [3].

Currently, there is a lack of prospective studies to support guidelines on the treatment of older patients with RA [4]. Comorbidities are more prevalent in older patients with RA than in younger patients $[5,6]$, and complications can reduce the therapeutic efficacy of DMARDs [7]. Consequently, data from real-world clinical practice show that low disease activity is only achieved in approximately half of older patients with RA [8]. Moreover, the incidence of adverse events, including infectious diseases, is greater in older patients than in younger patients with RA [9-12]. Although older patients with RA are at a greater risk of infection, appropriate management of disease activity can reduce this risk [13]. Thus, treatment options should be established specifically for this group of patients with RA.

Abatacept selectively inhibits $\mathrm{T}$ cell activation and therefore suppresses the production of inflammatory cytokines and other pro-inflammatory mediators [14]. Clinical trials have shown that the efficacy of abatacept is similar to that of other bDMARDs [15-17]. Furthermore, the incidence of severe infections after abatacept treatment has been reported to be similar in older and younger patients with RA [18], 
whereas greater incidences of severe infections have been observed in older patients with RA who received tumor necrosis factor inhibitors and an interleukin- 6 inhibitor $[19,20]$. Compared with treatment involving other bDMARDs, abatacept treatment is also associated with a lower risk of severe infection $[21,22]$. Thus far, frequent use and long-term maintenance of abatacept treatment have been reported in older patients with RA [23, 24]; however, the efficacy of abatacept in older patients with RA has primarily been demonstrated via retrospective comparisons with younger patients $[25,26]$. This prospective study was therefore performed to compare the efficacy of abatacept in older patients vs. younger patients with a history of being refractory to conventional synthetic DMARDs (csDMARDs). We also compared the efficacy of abatacept with that of csDMARDs in older and younger csDMARD-refractory patients with RA.

\section{METHODS}

\section{Study Design and Patients}

This multicenter, open-label, prospective, observational study (Investigation of the Effects of Abatacept on Rheumatoid Arthritis: Analysis of Efficacy on Arthritis and Atherosclerosis [ABT-ATS study]) compared the efficacy of abatacept with csDMARDs in older and younger patients with RA and a history of being refractory to csDMARDs. The study was conducted at 31 centers in Japan (see the Appendix in the electronic supplementary material). The study protocol was approved by the ethics committees of the Faculty of Medicine, Toho University (Approval number: A20114_A17112_A16017_27038), Teikyo University (Approval number: 14-061) and ethics committees of collaborative institutions; this study was performed in accordance with the Helsinki Declaration of 1964 and its later amendments, and all enrolled patients provided written informed consent to participate. This study was registered with the University Hospital Medical Information Network (UMIN000014913). Patient enrollment began in
August 2014 and concluded in March 2018. The final follow-up for the last patient was performed in April 2021.

The inclusion criteria were as follows: age $\geq 20$ years, a diagnosis of RA using the 2010 American College of Rheumatology/European League Against Rheumatism (EULAR) classification criteria [27], a history of being refractory to csDMARDs, and bio-naïve (i.e., had not previously been treated with bDMARDs). The exclusion criteria included the presence of malignant tumors, active infections, pregnancy, and the patient being deemed by the physician to be a poor fit for this study.

Baseline characteristics including age, sex, radiographic stage, laboratory assessments, clinical assessments (including patient and physician scores, disease activity scores and indices, and the Health Assessment Questionnaire), and medications were all recorded (see Table 1).

\section{Study Interventions}

Treatment was assigned at the discretion of the treating physician, with patients either starting therapy with abatacept, adding an additional csDMARD to their regimen, or switching to a new csDMARD. Patients were categorized into the following four groups: older ( $\geq 65$ years) patients who received abatacept (AO group), younger (20-64 years) patients who received abatacept (AY group), older patients who received csDMARDs (CO group), and younger patients who received csDMARDs (CY group). The abatacept intravenous formulation was administered at the start of treatment (baseline), at 2 and 4 weeks after baseline, and then at 4-week intervals. The recommended dose [28] was $500 \mathrm{mg}$ for patients weighing $<60 \mathrm{~kg}$, $750 \mathrm{mg}$ for patients weighing $\geq 60 \mathrm{~kg}$ and $\leq 100 \mathrm{~kg}$, and $1000 \mathrm{mg}$ for patients weighing $>100 \mathrm{~kg}$ (all doses were administered in $100 \mathrm{ml}$ of $0.9 \% \mathrm{NaCl}$ aqueous solution). At the treating physician's discretion, subcutaneous abatacept could be administered concurrently with intravenous abatacept (i.e., immediately after intravenous administration on the same day) at a dosage of $125 \mathrm{mg}$ weekly (administered in $1 \mathrm{ml}$ of $0.9 \% \mathrm{NaCl}$ aqueous solution) [28]; 
Table 1 Baseline characteristics of patients with rheumatoid arthritis, according to age group and treatment

\begin{tabular}{|c|c|c|c|c|c|}
\hline & \multicolumn{2}{|l|}{ Abatacept } & \multicolumn{2}{|l|}{ csDMARDs } & \multirow{2}{*}{$\begin{array}{l}\text { Total } \\
n=202\end{array}$} \\
\hline & AY, $n=47$ & AO; $n=67$ & $\overline{C Y} ; n=40$ & $\mathrm{CO} ; n=48$ & \\
\hline Age (years) & $52.5 \pm 10.7$ & $74.7 \pm 5.7^{\mathrm{c}}$ & $52.2 \pm 9.4$ & $74.0 \pm 6.3$ & $64.9 \pm 13.6$ \\
\hline Female sex & $38(80.9)$ & $53(79.1)$ & $35(87.5)$ & $41(85.4)$ & $167(82.7)$ \\
\hline Disease duration (years) & $6.8 \pm 9.4$ & $9.8 \pm 11.3$ & $5.3 \pm 6.4$ & $9.3 \pm 10.7$ & $8.1 \pm 10.0$ \\
\hline Steinbrocker stage I/II/III/IV & $17 / 14 / 10 / 6$ & $16 / 19 / 18 / 14$ & $24 / 11 / 3 / 2$ & $17 / 13 / 13 / 5$ & $74 / 57 / 44 / 27$ \\
\hline Steinbrocker class I/II/III/IV & $8 / 36 / 3 / 0$ & $11 / 43 / 12 / 1$ & $28 / 11 / 1 / 0$ & $28 / 16 / 4 / 0^{b}$ & $75 / 106 / 20 / 1$ \\
\hline Swollen joint count & $5.6 \pm 3.1$ & $6.3 \pm 4.9$ & $3.6 \pm 2.7^{\mathrm{a}}$ & $3.8 \pm 2.6^{\mathrm{b}}$ & $5.0 \pm 3.8$ \\
\hline Tender joint count & $5.2 \pm 4.1$ & $6.4 \pm 5.1$ & $2.1 \pm 2.7^{\mathrm{a}}$ & $2.4 \pm 3.5^{\mathrm{b}}$ & $4.3 \pm 4.5$ \\
\hline CRP level (mg/dL) & $1.6 \pm 3.2$ & $2.2 \pm 2.5$ & $0.4 \pm 0.4^{\mathrm{a}}$ & $0.6 \pm 1.1^{\mathrm{b}}$ & $1.3 \pm 2.3$ \\
\hline $\operatorname{ESR}(\mathrm{mm} / \mathrm{h})$ & $30.8 \pm 27.4$ & $49.3 \pm 28.3^{c}$ & $17.4 \pm 14.5^{a}$ & $25.7 \pm 18.7^{\mathrm{b}}$ & $33.1 \pm 26.6$ \\
\hline Patient's global VAS score (mm) & $47.9 \pm 25.3$ & $52.7 \pm 23.7$ & $29.3 \pm 20.7^{a}$ & $38.4 \pm 28.3^{\mathrm{b}}$ & $43.6 \pm 26.1$ \\
\hline Physician's global VAS score $(\mathrm{mm})$ & $43.7 \pm 20.5$ & $48.0 \pm 19.4$ & $28.7 \pm 15.8^{a}$ & $30.4 \pm 13.4^{\mathrm{b}}$ & $39.0 \pm 19.5$ \\
\hline DAS28-ESR & $4.6 \pm 1.1$ & $5.2 \pm 1.2^{\mathrm{c}}$ & $3.3 \pm 0.9^{\mathrm{a}}$ & $3.8 \pm 1.1^{\mathrm{b}}$ & $4.4 \pm 1.3$ \\
\hline DAS28-CRP & $4.1 \pm 1.1$ & $4.6 \pm 1.2^{\mathrm{c}}$ & $2.9 \pm 0.8^{\mathrm{a}}$ & $3.2 \pm 1.0^{\mathrm{b}}$ & $3.8 \pm 1.2$ \\
\hline SDAI & $21.5 \pm 9.8$ & $24.9 \pm 11.8$ & $11.8 \pm 5.9^{\mathrm{a}}$ & $13.7 \pm 7.5^{\mathrm{b}}$ & $18.8 \pm 10.9$ \\
\hline CDAI & $19.9 \pm 8.6$ & $22.7 \pm 10.9$ & $11.5 \pm 5.8^{\mathrm{a}}$ & $13.0 \pm 7.2^{b}$ & $17.5 \pm 9.9$ \\
\hline HAQ score & $0.6 \pm 0.6$ & $1.0 \pm 0.7^{\mathrm{c}}$ & $0.2 \pm 0.4^{\mathrm{a}}$ & $0.6 \pm 0.9^{\mathrm{b}}$ & $0.7 \pm 0.7$ \\
\hline RF-positive & $39(83.0)$ & $58(86.6)$ & $30(75.0)$ & $33(68.8)^{\mathrm{b}}$ & $160(79.2)$ \\
\hline Anti-CCP-positive & $41(87.2)$ & $55(82.1)$ & $31(77.5)$ & $34(70.8)$ & $161(79.7)$ \\
\hline Interstitial pneumonia & $1(2.1)$ & $14(20.1)$ & $3(7.5)$ & $3(6.3)$ & $21(10.4)$ \\
\hline Steroid use & $17(36.2)$ & $35(52.2)$ & $10(25.0)$ & $17(35.4)$ & $79(39.1)$ \\
\hline Prednisolone (mg) & $4.9 \pm 3.7$ & $5.8 \pm 4.4$ & $3.7 \pm 1.6$ & $4.0 \pm 1.3^{\mathrm{b}}$ & $4.9 \pm 3.5$ \\
\hline MTX use & $38(80.9)$ & $37(55.2)^{c}$ & $28(70.0)$ & $23(47.9)$ & $126(62.4)$ \\
\hline Salazosulfapyridine & $11(23.4)$ & $15(22.4)$ & $2(5.0)^{\mathrm{a}}$ & $10(20.8)$ & $38(18.8)$ \\
\hline Bucillamine & $6(12.8)$ & $4(6.0)$ & $9(22.5)$ & $11(22.9)^{\mathrm{b}}$ & $30(14.9)$ \\
\hline Tacrolimus & $2(4.3)$ & $1319.4)^{c}$ & $1(2.5)$ & $4(8.3)$ & $20(9.9)$ \\
\hline Iguratimod & $5(10.6)$ & $7(10.4)$ & $2(5.0)$ & $1(2.1)$ & $15(7.4)$ \\
\hline Mizoribine & $0(0)$ & $1(1.5)$ & $0(0)$ & $0(0)$ & $1(0.5)$ \\
\hline \multicolumn{6}{|c|}{ Additional treatment initiated during this study } \\
\hline Abatacept & $47(100)$ & $67(100)$ & - & - & \\
\hline MTX & - & - & $10(25.0)$ & $10(20.8)$ & \\
\hline Salazosulfapyridine & - & - & $2(5.0)$ & $7(14.6)$ & \\
\hline
\end{tabular}


Table 1 continued

\begin{tabular}{|c|c|c|c|c|c|}
\hline & \multicolumn{2}{|l|}{ Abatacept } & \multicolumn{2}{|l|}{ csDMARDs } & \multirow{2}{*}{$\begin{array}{l}\text { Total } \\
n=202\end{array}$} \\
\hline & $\mathrm{AY}, n=47$ & AO; $n=67$ & $\mathrm{CY} ; n=40$ & $\mathrm{CO} ; n=48$ & \\
\hline Bucillamine & - & - & $11(27.5)$ & $10(20.8)$ & \\
\hline Tacrolimus & - & - & $2(5.0)$ & $5(10.4)$ & \\
\hline Iguratimod & - & - & $14(35.0)$ & $14(29.2)$ & \\
\hline Leflunomide & - & - & $1(2.5)$ & $2(4.2)$ & \\
\hline
\end{tabular}

Results are shown as mean \pm standard deviation or $n$ (\%). Student's $t$ test was used for continuous variables. The Chisquared test was used for categorical variables. $p<0.05$, ${ }^{\mathrm{a}} \mathrm{AY}$ vs. $\mathrm{CY},{ }^{\mathrm{b}} \mathrm{AO}$ vs. $\mathrm{CO},{ }^{\mathrm{c}} \mathrm{AO}$ vs. $\mathrm{AY}$

$A O$ older patients receiving abatacept, $A Y$ younger patients receiving abatacept, $C C P$ cyclic citrullinated peptide, $C D A I$ Clinical Disease Activity Index, $C O$ older patients receiving conventional synthetic disease-modifying antirheumatic drugs, $C R P$ C-reactive protein, $C Y$ younger patients receiving conventional synthetic disease-modifying antirheumatic drugs, csDMARDs conventional synthetic disease-modifying antirheumatic drugs, DAS28 disease activity score in 28 joints, ESR erythrocyte sedimentation rate, $H A Q$ Health Assessment Questionnaire, $M T X$ methotrexate, $R F$ rheumatoid factor, $S D A I$ Simple Disease Activity Index, $V A S$ visual analog scale

subcutaneous abatacept could be administered alone, also at the treating physician's discretion. During the study period, patients could receive csDMARDs, glucocorticoids, and/or non-steroidal anti-inflammatory drugs; these treatments could be added or changed, or their dosages could be modified based on the treating physician's discretion. Patients were withdrawn from the study if abatacept treatment was discontinued or if any bDMARDs were initiated in those patients receiving csDMARDs.

\section{Study Endpoints}

For both abatacept and csDMARD treatments, clinical efficacy was evaluated at baseline, week 12 , and week 24 . The primary study endpoint was a good response according to the EULAR erythrocyte sedimentation rate (ESR) response criteria at week 24. Additional efficacy assessments included a good or moderate response according to the EULAR response criteria at week 24, as well as changes from baseline (at week 24) in disease activity score as measured across 28 joints using the erythrocyte sedimentation rate (DAS28-ESR), Simple Disease Activity Index (SDAI), and Clinical Disease Activity Index (CDAI). Examination of abatacept efficacy was further evaluated according to concomitant methotrexate (MTX) treatment status. The overall ABT-ATS study also assessed the efficacy of abatacept on atherosclerosis for 3 years from baseline; however, these data are not presented in this report.

Additionally, adverse events were recorded during the study. Serious adverse events were defined as a fatal event, a life-threatening event, a hospitalization event, a permanent or significant disability event, or any other important medical event.

\section{Statistical Analysis}

Analyses were performed using the per-protocol dataset. Data are expressed as mean \pm standard deviation. All statistical analyses were performed using $\mathrm{R}$ software, version 3.6.2 (R Foundation for Statistical Computing, Vienna, Austria). Comparisons were performed using Student's $t$ test for continuous variables and the Chi-squared test for categorical variables. In all analyses, $p<0.05$ was considered statistically significant.

We performed a propensity-score matching analysis using baseline patient characteristics of tender joint counts, swollen joints counts, C-reactive protein (CRP), ESR, physician's visual analogue scale, patient's visual analogue scale, 


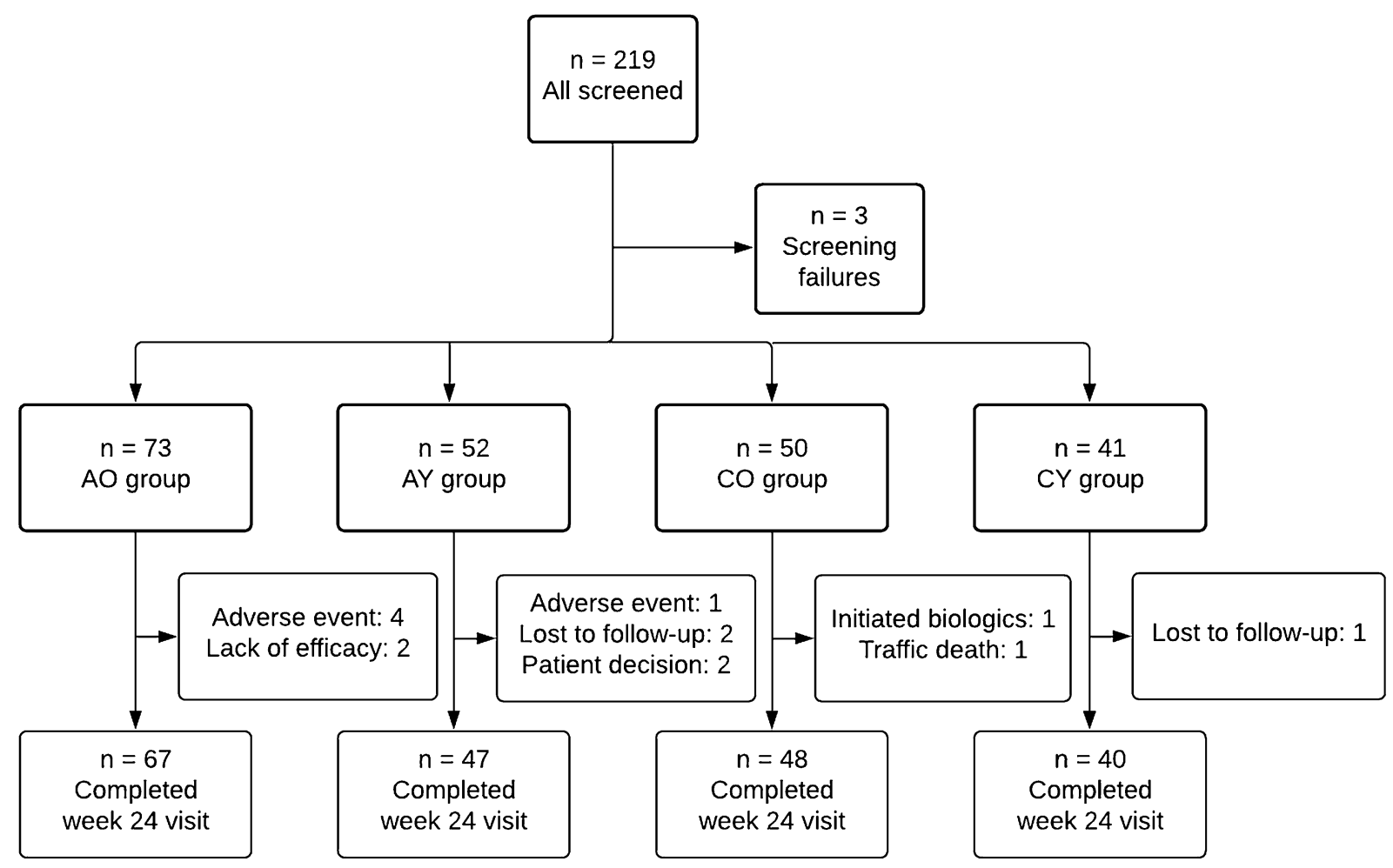

Fig. 1 Patient disposition. In total, 219 patients with rheumatoid arthritis were screened for inclusion; three dropped out because of screening failure (one in the $\mathrm{AO}$ group: entry without use of csDMARDs; one in the $\mathrm{CO}$ group: entry only after increased dose of MTX; one in the AO group: entry with a history of biologics treatment). Six patients in the AO group, five patients in the AY group, two patients in the CO group, and one patient in the CY group dropped out for the reasons shown. Thus, 202

proportion of MTX use, proportion of glucocorticoid use, disease duration, rheumatoid factor, and anti-cyclic citrullinated peptide antibody. Matching was performed with a 1:1 matching protocol using nearest-neighbor matching without replacement and with a caliper width, which was 1 standard deviation of logarithm odds for ABT group.

\section{RESULTS}

\section{Patient Characteristics}

In total, 219 patients with RA were screened for inclusion in this study. Of these, 202 had been patients who had been observed for 24 weeks were included in the analysis (per-protocol set). $A O$ older patients receiving abatacept, $A Y$ younger patients receiving abatacept, $C O$ older patients receiving conventional synthetic disease-modifying antirheumatic drugs, $c s D M A R D s$ conventional synthetic disease-modifying antirheumatic drugs, $C Y$ younger patients receiving conventional synthetic disease-modifying antirheumatic drugs, MTX methotrexate

observed for 24 weeks and were included in the analysis (AO group, 67 patients; AY group, 47 patients; CO group, 48 patients; and CY group, 40 patients) (Fig. 1). Detailed baseline characteristics are provided in Table 1 and Supplementary Table S1. Most patients were women $(82.7 \%)$ and the mean age ( \pm standard deviation) was $64.9 \pm 13.6$ years. The overall proportions of rheumatoid factor-positive and anticyclic citrullinated peptide antibody-positive patients were $79.2 \%$ and $79.7 \%$, respectively. In both younger and older patients, those receiving abatacept had greater disease activity (DAS28, CDAI, and SDAI) and greater Health Assessment Questionnaire scores at baseline, compared with those receiving csDMARDs. The 


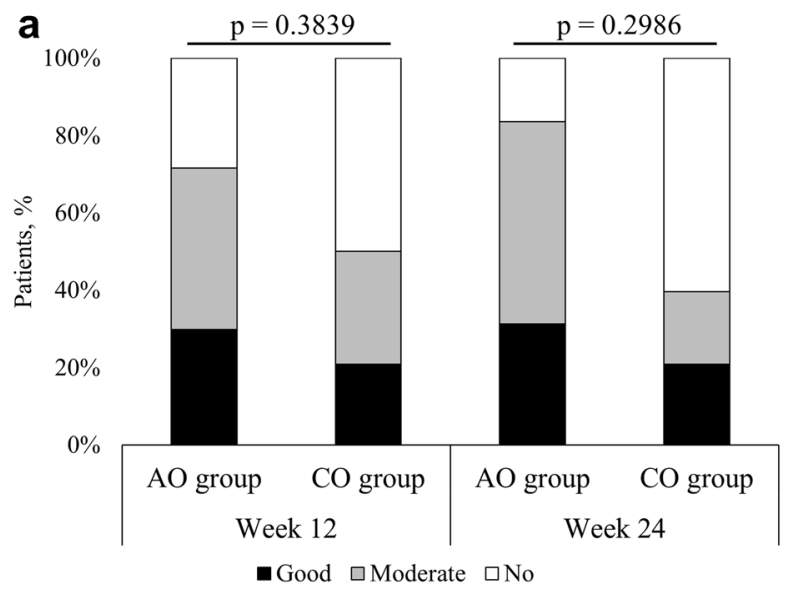

Fig. 2 Proportions of patients with rheumatoid arthritis who had the indicated EULAR responses at weeks 12 and 24. a Comparison between AO and CO groups. b Comparison between AY and CY groups. Proportions of patients with a EULAR good response vs. those with a EULAR moderate or no response were compared using the Chi-squared test. $A O$ older patients receiving abatacept,

proportion of patients using MTX tended to be greater among those receiving abatacept than among those receiving csDMARDs; this proportion was significantly lower in the AO group than in the AY group. The proportions of patients with interstitial pneumonia at baseline were $20.1 \%(14 / 67)$ in the AO group, $2.1 \%$ (1/ $47)$ in the AY group, $6.3 \%(3 / 48)$ in the CO group, and $7.5 \%(3 / 40)$ in the CY group.

\section{Comparison of Treatment Efficacy: Older Patients}

Similar proportions of patients in the $\mathrm{AO}$ and CO groups had a EULAR good response at week 24 (31.3 vs. $20.8 \%$, odds ratio [OR]: $1.735,95 \%$ confidence interval [CI] 0.729-4.128, $p=0.2986$ ) (Fig. 2a). A significantly greater proportion of patients in the $\mathrm{AO}$ group achieved a EULAR good or moderate response at week 24, compared with the CO group (83.6 vs. $39.6 \%$, OR: 7.770, 95\% CI 3.264-18.500, $p<0.0001)$. At week 12, more patients in the AO group also had a EULAR good or moderate response, compared with the $\mathrm{CO}$ group (71.6 vs. $50.0 \%$, OR: $2.526,95 \%$ CI 1.163-5.490, $p=0.0300)$. At weeks 12 and 24 , the respective changes in

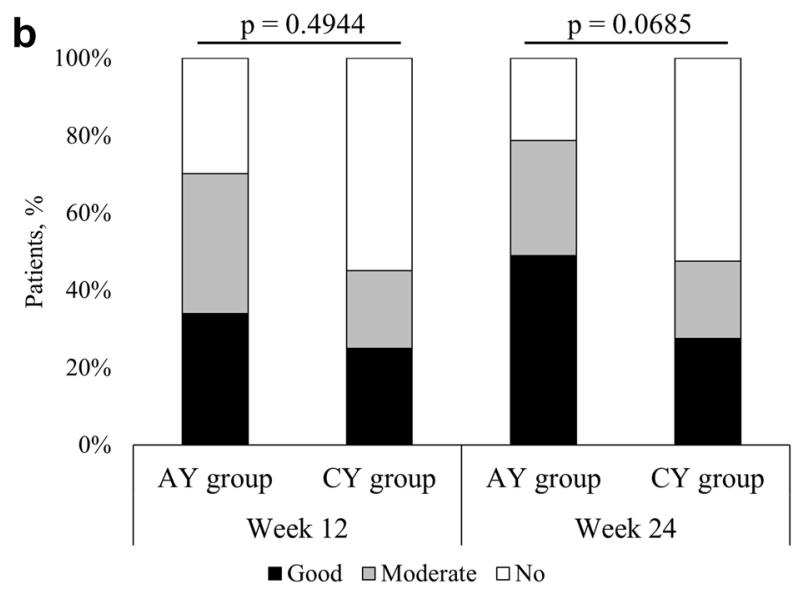

$A Y$ younger patients receiving abatacept, $C O$ older patients receiving conventional synthetic disease-modifying antirheumatic drugs, csDMARDs conventional synthetic disease-modifying antirheumatic drugs, $C Y$ younger patients receiving conventional synthetic disease-modifying antirheumatic drugs, EULAR European League Against Rheumatism

DAS28-ESR from baseline were $-1.639 \pm 1.354$ and $-1.900 \pm 1.205$ in the AO group, while they were $-0.645 \pm 0.908$ and $-0.602 \pm$ 0.881 in the CO group $(p<0.0001$ for both weeks 12 and 24). At weeks 12 and 24, the respective changes in SDAI from baseline were $-13.624 \pm 12.480 \quad$ and $-15.577 \pm$ 12.240 in the AO group, while they were $-3.966 \pm 5.484$ and $-4.506 \pm 6.495$ in the CO group $(p<0.0001$ for both weeks 12 and 24). Notably, changes in DAS28-ESR and SDAI from baseline at weeks 12 and 24 were both significantly greater in the AO group than in the CO group (Fig. 3a, b). Serial changes of each absolute numbers of DAS28-ESR and SDAI are shown in Supplementary Figure S1a, b. Changes in DAS28-CRP and CDAI at week 24 were also greater in the AO group than in the CO group (DAS28-CRP: $-1.895 \pm 1.252$ vs. $-0.626 \pm 0.818, p<0.0001 ;$ CDAI -14.048 \pm 11.256 vs. $-4.246 \pm 6.134, p<0.0001)$.

\section{Comparison of Treatment Efficacy: Younger Patients}

A greater proportion of patients in the AY group tended to achieve a EULAR good response at 
a

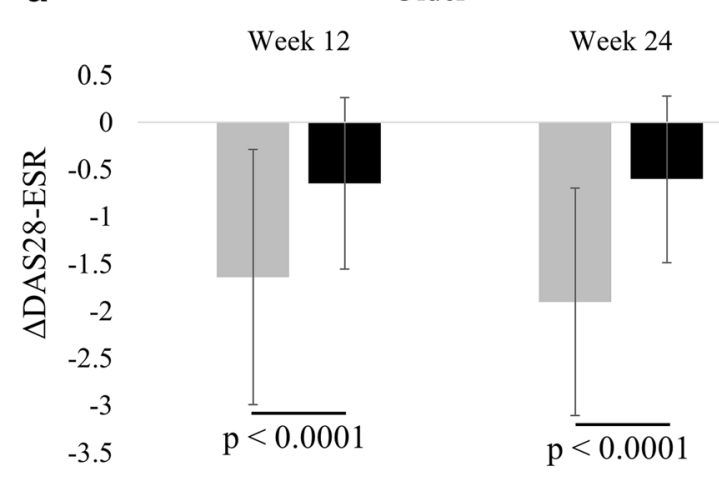

b

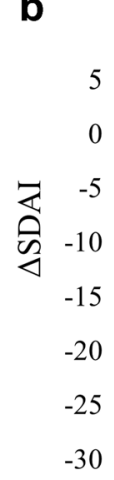

Older

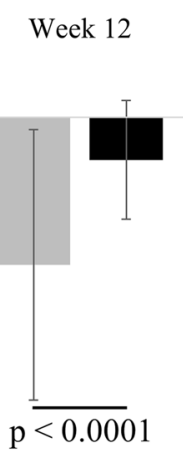

C

d

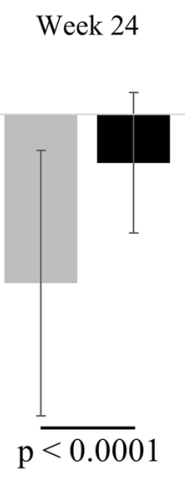

Fig. 3 Changes in DAS28-ESR (a, c) and SDAI (b, d) from baseline at weeks 12 and 24 during treatment of older (a, b) and younger (c, d) patients with rheumatoid arthritis. Error bars represent standard deviations. Comparisons between groups were performed using Student's

week 24, compared with the CY group (48.9 vs. 27.5\%, OR: 2.527, 95\% CI 1.028-6.210, $p=0.0685$ ) (Fig. 2b). A significantly greater proportion of patients in the AY group achieved a EULAR good or moderate response at week 24, compared with the CY group (78.7 vs. $47.5 \%$, OR: $4.089,95 \%$ CI 1.606-10.411, $p=0.0050$ ). At week 12, more patients in the AY group also had a EULAR good or moderate response, compared with the CY group (70.2 vs. $45.0 \%$, OR: $2.881,95 \%$ CI $1.192-6.963, p=0.0307)$. At weeks 12 and 24, the respective changes in DAS28-ESR from baseline were $-1.460 \pm 1.291$ and $-1.676 \pm 1.470$ in the AY group, while they were $-0.548 \pm 0.845$ and $-0.761 \pm$ 1.137 in the CY group ( $p=0.0002$ for week 12 and $p=0.0015$ for week 24). At weeks 12 and 24 , the respective changes in SDAI from

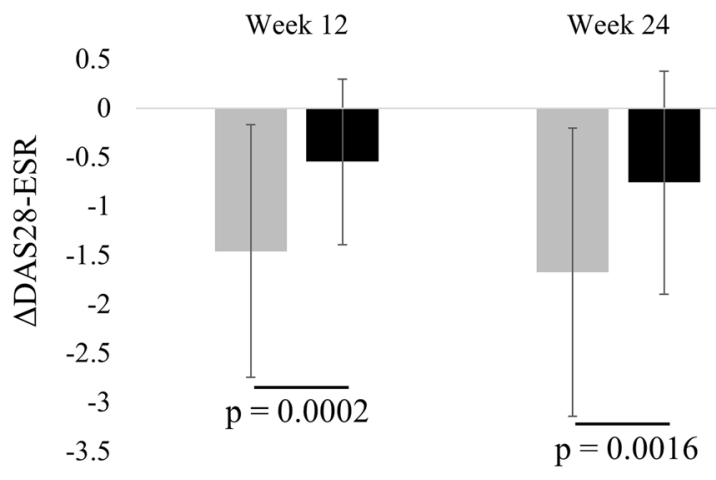

Younger

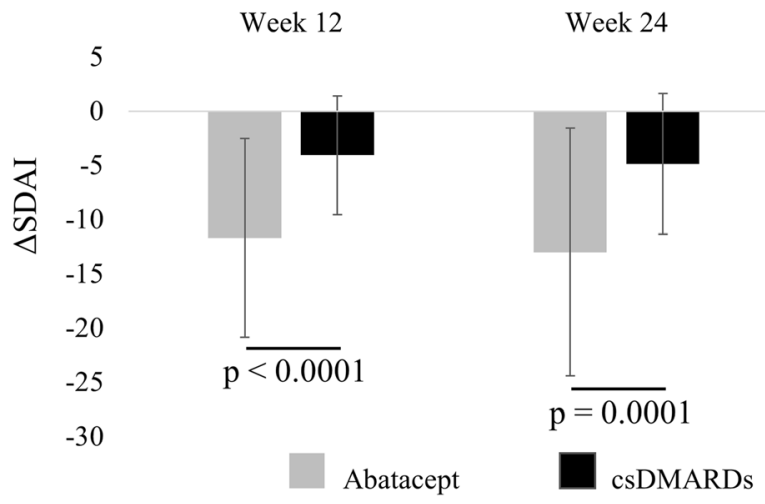

$t$ test. $c s D M A R D s$ conventional synthetic disease-modifying antirheumatic drugs, DAS28-ESR disease activity score in 28 joints using erythrocyte sedimentation rate, $S D A I$ Simple Disease Activity Index

baseline were $-11.688 \pm 9.176$ and -13.013 \pm 11.435 in the AY group, while they were $-4.079 \pm 5.271$ and $-4.865 \pm 7.162$ in the CY group $(p<0.0001$ for week 12 and $p=0.0001$ for week 24). Importantly, changes in DAS28-ESR and SDAI from baseline at weeks 12 and 24 were both significantly greater in the AY group than in the CY group (Fig. 3c, d). Serial changes of each absolute numbers of DAS28-ESR and SDAI are shown in Supplementary Figure S1c, d. Changes in DAS28-CRP and CDAI were also greater in the AY group than the CY group (DAS28-CRP: $-1.626 \pm 1.333$ vs. $-0.642 \pm 1.040, \quad p=0.0002$; CDAI: -11.979 \pm 10.612 vs. $-4.759 \pm 6.941, p=0.0003)$. 

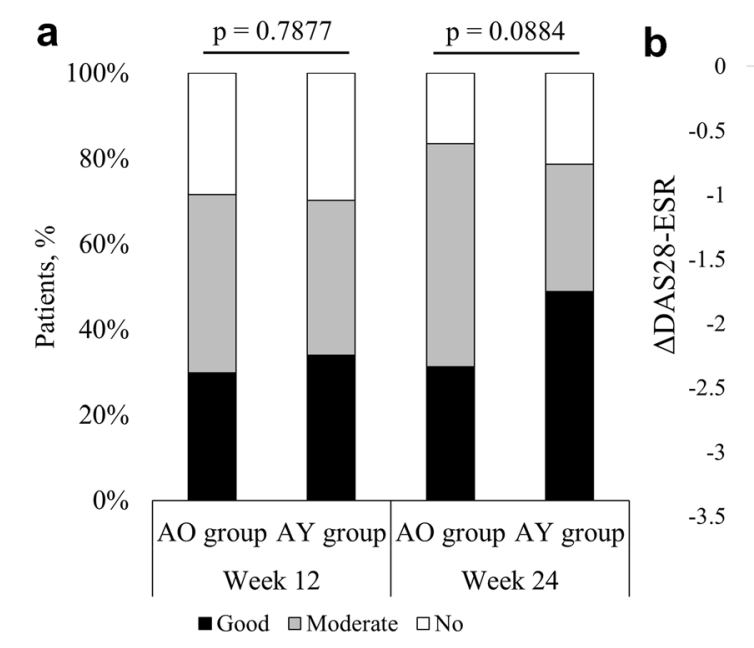

Fig. 4 Comparison of efficacy between $\mathrm{AO}$ and $\mathrm{AY}$ groups at weeks 12 and 24 during treatment of patients with rheumatoid arthritis. a Proportions of patients with indicated EULAR responses. Proportions of patients with a EULAR good response vs. those with a EULAR moderate or no response were compared using the Chisquared test. Changes in b DAS28-ESR and $\mathbf{c}$ SDAI from

\section{Comparison of Treatment Efficacy: All Patients}

A significantly greater proportion of patients in the abatacept overall group $(\mathrm{AO}+\mathrm{AY})$ achieved a EULAR good response at week 24, compared with the csDMARDs overall group (CO + CY) (Supplementary Figure S2a). A significantly greater proportion of patients in the abatacept overall group also achieved a EULAR good or moderate response at week 24, compared with the csDMARDs overall group. At week 12, there was a significant difference in the proportion of patients with a EULAR good or moderate response between the abatacept and csDMARDs overall groups. At weeks 12 and 24, changes in DAS28-ESR and SDAI from baseline were both significantly greater in the abatacept overall group than in the csDMARDs overall group (Supplementary Figure S2b, c). Serial changes of each absolute numbers of DAS28-ESR and SDAI are shown in Supplementary Figure S1e, f. Changes in disease activity in 28 joints using DAS28-CRP and CDAI were also greater in the abatacept overall group than in the csDMARDs

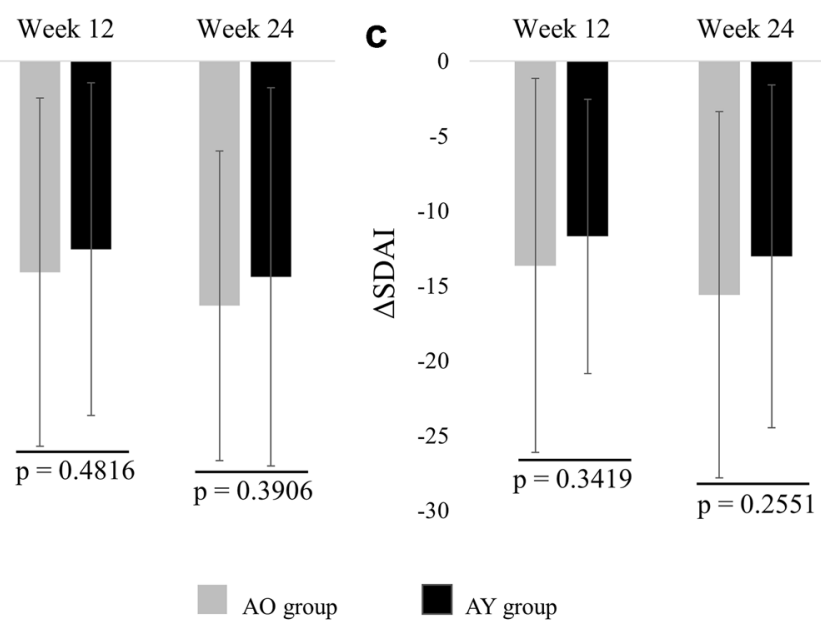

baseline at weeks 12 and 24. Error bars represent standard deviations. Comparisons between groups were performed using Student's $t$ test. $A O$ older patients receiving abatacept, $A Y$ younger patients receiving abatacept, $D A S 28-E S R$ disease activity score in 28 joints using erythrocyte sedimentation rate, EULAR European League Against Rheumatism, SDAI Simple Disease Activity Index

overall group. Finally, the steroid-sparing effect was significantly greater in the abatacept overall group than in the csDMARDs overall group. Detailed results for the abatacept and csDMARDs overall groups are presented in Supplementary Table S2.

\section{Comparison of Abatacept Efficacy by Age Group}

Assessment of abatacept efficacy in younger and older patients showed that a numerically smaller proportion of patients in the $\mathrm{AO}$ group had a EULAR good response at week 24 compared with the AY group, although this difference did not reach statistical significance (31.3 vs. $48.9 \%$, OR: 0.476 , 95\% CI $0.220-1.029, p=0.0884$ ) (Fig. 4a). Similar proportions of patients in the $\mathrm{AO}$ and AY groups had EULAR good or moderate responses ( 83.6 vs. $78.7 \%$, OR: $1.376,95 \%$ CI $0.531-3.564, p=0.6794)$. At week 12 , these proportions were similar in the $\mathrm{AO}$ and $\mathrm{AY}$ groups (good response: 29.9 vs. 34.0\%, OR: $0.824,95 \%$ CI 0.371-1.832, $p=0.7877$; good or 
moderate response: 71.6 vs. $70.2 \%$, OR: 1.072 , 95\% CI 0.472-2.434, $p=1.0000$ ). Other indices of disease activity did not differ significantly between groups. Specifically, at weeks 12 and 24, respective changes in DAS28-ESR from baseline were $-1.639 \pm 1.354$ and $-1.900 \pm$ 1.205 in the AO group, while they were $-1.460 \pm 1.291$ and $-1.676 \pm 1.470$ in the AY group (Fig. 4b). At weeks 12 and 24, respective changes in SDAI from baseline were $-13.624 \pm 12.480$ and $-15.577 \pm 12.240$ in the AO group, while they were $-11.688 \pm$ 9.176 and $-13.013 \pm 11.435$ in the AY group (Fig. 4c). Serial changes of each absolute numbers of DAS28-ESR and SDAI are shown in Supplementary Figure S1g, h. Furthermore, changes in DAS28-CRP from baseline at week 24 were $-1.895 \pm 1.252$ in the $\mathrm{AO}$ group and $-1.626 \pm 1.333$ in the AY group $(p=0.2790)$. Changes in CDAI from baseline at week 24 were $-14.048 \pm 11.256$ in the $\mathrm{AO}$ group and $-11.979 \pm 10.612$ in the AY group $(p=0.3199)$.

\section{Analysis of Interactions Between MTX and Abatacept/csDMARDs Treatment}

Examination of abatacept efficacy in the AO and AY groups, stratified according to concomitant MTX treatment status, revealed that EULAR responses at week 24 were similar among patients in the AO group, regardless of MTX treatment (good response: AO with MTX $[n=37] 32.4$ vs. AO without MTX $[n=30]$ $30.0 \%$, OR: $1.120, \quad 95 \%$ CI $0.395-3.172$, $p=1.0000$; good or moderate response: $\mathrm{AO}$ with MTX 78.4 vs. AO without MTX 90.0\%, OR: 0.403 , 95\% CI 0.097-1.678, $p=0.3445$ ). Furthermore, EULAR responses were similar among patients in the AY group, regardless of MTX treatment (good response: AY with MTX $[n=38] 44.7$ vs. AY without MTX [ $n=9] 66.7 \%$, OR: 0.405 , 95\% CI $0.088-1.862, p=0.4165$; good or moderate response: AY with MTX 73.7 vs. AY without MTX 100.0\%, OR: 0.000, 95\% CI 0.000 -not calculable, $p=0.2000$ ). At week 24 , changes in DAS28-ESR from baseline were $1.792 \pm 1.175$ in the AO group with MTX and $-2.034 \pm 1.249$ in the $\mathrm{AO}$ group without
MTX ( $p=0.4226)$; the equivalent changes were $-1.560 \pm 1.548$ in the AY group with MTX and $-2.164 \pm 1.003$ in the AY group without MTX $(p=0.1660)$. Other indices of disease activity were not significantly different according to concomitant MTX treatment status.

Notably, the steroid-sparing effect tended to be greater in the $\mathrm{AO}$ group than in the $\mathrm{CO}$ group $\quad(-1.316 \pm 3.391 \mathrm{mg} /$ day $\quad$ vs. $-0.206 \pm 0.398 \mathrm{mg} / \mathrm{day}, p=0.0680)$. The steroid-sparing effect also tended to be greater in the AY group than in the $\mathrm{CY}$ group $(-1.367 \pm 2.334 \mathrm{mg} /$ day $\quad$ vs. $-0.111 \pm 0.333 \mathrm{mg} / \mathrm{day}, p=0.0584)$. The steroid-sparing effects did not significantly differ between the $\mathrm{AO}$ and $\mathrm{AY}$ groups $(-1.316 \pm 3.391 \mathrm{mg} /$ day vs.

$-1.367 \pm 2.334 \mathrm{mg} /$ day, $p=0.9522$ ).

\section{POST HOC ANALYSIS}

We used propensity-score matching to balance baseline characteristics in each comparison. For comparison between $\mathrm{AO}$ and $\mathrm{CO}$ groups, 31 matched pairs were statistically extracted, and for AY and CY groups, 25 pairs were extracted (Supplementary Table S3). At week 24, more patients in the AO group had a EULAR responses compared with the CO group (good response: 41.9 vs. $22.6 \%$, OR: 2.476 , $95 \%$ CI $0.821-7.465, p=0.1743$; good or moderate response: 74.2 vs. $45.2 \%$, OR: 3.491 , 95\% CI 1.196-10.191, $p=0.0383$ ) (Supplementary Figure S3a). Changes in DAS28-ESR and SDAI from baseline at week 24 were both significantly greater in the AO group than in the $\mathrm{CO}$ group (Supplementary Figure S3b, c). Whereas similar proportions of patients in the AY and CY groups had a EULAR good, or good or moderate response at week 24, and changes in DAS28-ESR and SDAI from baseline at week 24 were also similar (Supplementary Figure S3). Fifty-eight matched pairs of patients treated with abatacept overall group or csDMARDs overall group were statistically extracted (Supplementary Table S4). A significantly greater proportion of patients in the abatacept overall group achieved a EULAR responses compared with csDMARDs overall 
group at week 24 (good response: 46.6 vs. 29.3\%, OR: 2.101, 95\% CI 0.977-4.516, $p=0.0850$; good or moderate response: 72.4 vs. $51.7 \%$, OR: 2.450, 95\% CI 1.132-5.305, $p<0.0353$ ) (Supplementary Figure S4a). Changes in DAS28-ESR and SDAI from baseline at week 24 were both significantly greater in the abatacept overall group than in the csDMARDs overall group (Supplementary Figure S4b, c). For comparison between the AO and AY groups, 38 matched pairs were extracted (Supplementary Table S5). Similar proportions of patients in the AO and AY groups had a EULAR good, or good or moderate response at week 24 (Supplementary Figure S5a). Moreover, changes in DAS28ESR and SDAI from baseline were comparable between these 2 groups (Supplementary Figure S5b, c).

We also analyzed the steroid-sparing effects by the treatment after propensity-score matching. The abatacept overall group tended to have a higher steroid-sparing effect than the csDMARDs overall group $(-2.083 \pm 4.697$ vs. $-0.205 \pm 0.398 \mathrm{mg} /$ day, $p=0.1087)$. The AO group had a higher steroid-sparing effect than the CO group $(-2.250 \pm 5.413$ vs. $-0.273 \pm$ $0.467 \mathrm{mg} /$ day, $p=0.2332$ ), and also the AY group had a higher steroid-sparing effect than the CY group $(-2.000 \pm 2.708$ vs. $-0.200 \pm$ $0.447 \mathrm{mg} / \mathrm{day}, p=0.1316$ ), although the differences were not statistically significant. The AO group had a similar steroid-sparing effect compared to the AY group $(-2.417 \pm 5.351$ vs. $-1.708 \pm 2.509 \mathrm{mg} /$ day, $p=0.6836$ ).

We next compared the efficacy of abatacept between elderly-onset RA (EORA) and youngonset RA (YORA). The overall abatacept-treated patients were divided into two groups, EORA (onset age of 65 years or older, $n=62$ ) and YORA (onset age of less than 65 years, $n=140$ ). EULAR good, or good or moderate response rate are similar in EORA and YORA (Supplementary Figure S6a). However, change in SDAI from baseline at week 24 was significantly greater in the EORA than in the YORA (Supplementary Figure S6c).

Finally, in order to evaluate the response to abatacept according to age more distinctly, we further compared between really older patients (70 years old or older, $n=53$ ) and very young patients (50 years old or younger, $n=14$ ). There were no statistically significant differences in the rates of EULAR good, or good or moderate response, or changes in DAS28-ESR and SDAI from baseline (Supplementary Figure S7).

\section{Adverse Events}

During the study period, 29 adverse events (including nine serious adverse events) occurred (Table 2). Six patients discontinued treatment due to adverse events; four of these patients were in the AO group and the events were bladder cancer, pneumonia, rash, and septic arthritis. One patient in the AY group discontinued the study due to abatacept hypersensitivity and one patient in the CO group died in a traffic accident. Other serious adverse events that did not result in study discontinuation were prostate cancer in the AO group, pulmonary Mycobacterium avium complex infection in the AY group, and diabetes mellitus in the CO group (all $n=1$ ).

\section{DISCUSSION}

This study prospectively compared the efficacies of abatacept and csDMARDs in older and younger patients with RA and a history of being refractory to csDMARDs using real-world clinical data. We demonstrated that the use of abatacept was more efficacious than the addition/change of csDMARDs in older and younger patients with RA who were refractory to csDMARDs and were bio-naïve. Furthermore, we found that the efficacies of abatacept at weeks 12 and 24 were similar in older and younger patients with RA.

In this study, abatacept was selected by physicians for patients with greater disease activity and greater Health Assessment Questionnaire scores, compared with patients who received csDMARDs. The proportion of patients with steroid use was highest in the AO group $(52.2 \%)$, and the steroid dose was also highest in the AO group $(5.8 \mathrm{mg} /$ day). Moreover, the $\mathrm{AO}$ group had the highest rate of interstitial pneumonia at baseline; no patients in either group developed interstitial pneumonia after 
Table 2 Summary of adverse events during treatment of patients with rheumatoid arthritis

\begin{tabular}{|c|c|c|c|c|}
\hline & \multicolumn{2}{|c|}{ Abatacept } & \multicolumn{2}{|c|}{ csDMARDs } \\
\hline & $\overline{\mathrm{AY}}$ & AO & $\overline{\mathrm{CY}}$ & $\mathrm{CO}$ \\
\hline Total number of adverse events & 8 & 11 & 5 & 5 \\
\hline Elevated liver enzymes & & & 3 & 1 \\
\hline Oral ulcer & 2 & 1 & & \\
\hline Nasopharyngitis & & 2 & & \\
\hline Bronchitis & & 1 & 1 & \\
\hline Gastritis & 1 & & & 1 \\
\hline Rash & & 1 & & \\
\hline Depression & & 1 & & \\
\hline Bursitis & 1 & & & \\
\hline Tonsillitis & 1 & & & \\
\hline Folliculitis & 1 & & & \\
\hline Bronchiectasis & & & & 1 \\
\hline Diarrhea & & & 1 & \\
\hline Serious adverse events & 2 & 5 & 0 & 2 \\
\hline Prostate cancer & & 1 & & \\
\hline Bladder cancer & & 1 & & \\
\hline Pneumonia & & 1 & & \\
\hline Rash & & 1 & & \\
\hline Septic arthritis & & 1 & & \\
\hline Hypersensitivity & 1 & & & \\
\hline Pulmonary MAC infection & 1 & & & \\
\hline Diabetes mellitus & & & & 1 \\
\hline Death & & & & 1 (due to traffic accident) \\
\hline
\end{tabular}

$A O$ older patients receiving abatacept, $A Y$ younger patients receiving abatacept, $C O$ older patients receiving conventional synthetic disease-modifying antirheumatic drugs, $C Y$ younger patients receiving conventional synthetic disease-modifying antirheumatic drugs, MAC Mycobacterium avium complex

the start of the study. Nonetheless, disease activity was significantly reduced in the $A O$ group; notably, steroid dose was also reduced in a manner similar to that observed in the AY group. Unlike the synergistic effects of tumor necrosis factor inhibitors, the efficacy of abatacept is not substantially enhanced when it is administered in combination with MTX [29-33]. Of note, there appears to be a benefit of
MTX in combination with abatacept for patients with greater disease activity or during long-term treatment [34-36]. In the present study, we found no differences in abatacept efficacy between the AO and AY groups, regardless of concomitant MTX treatment. This confirmation of the efficacy of abatacept in realworld conditions, where a small proportion of 
patients receive MTX, is a clinically significant finding.

Our results showed that abatacept efficacy was similar in older and younger patients with RA. Also, the abatacept efficacy was similar in really older (70 years old or older) and very young (50 years old or younger) patients and in EORA (onset age of 65 years or older) and YORA (onset age of less than 65 years) by post hoc analysis. Several large-scale clinical trials have reported the efficacy of abatacept in patients with a mean age of 45.4-53.4 years [34, 37-39]. Previous retrospective studies have also observed that abatacept efficacy was similar in older and younger patients [18, 36, 40, 41]. Our prospective data thus confirm these previous findings. Consistent with our results, a prospective study by Sekiguchi et al. [42] also showed that the efficacy of abatacept in bionaïve older patients with RA was similar to its efficacy in younger patients [42]; however, this was a subgroup analysis of older and younger patients with RA who were not provided with additional treatment options (e.g., csDMARDs). In contrast, our study prospectively enrolled four groups of older and younger patients who either received abatacept or csDMARDs. As such, the inclusion of patients who received csDMARDs does provide clinically relevant insights into the benefits of abatacept in older and younger patients.

The number of infections was relatively small in all groups, although the AO group tended to have a greater incidence of infections including serious infections such as pneumonia $(n=1)$ and septic arthritis $(n=1)$. Furthermore, a pulmonary Mycobacterium avium complex infection was also observed in the AY group. Although the number of patients in this study was small and the duration was short, these results suggest that abatacept is relatively well tolerated in older patients. This is also consistent with the low incidence of infections in a recently published large retrospective cohort study of Japanese patients with RA undergoing treatment with abatacept [43]. However, it was reported that the treatment with abatacept promoted Staphylococcal septic arthritis, whereas TNF inhibitor developed kidney abscess in mice intravenously inoculated with
Staphylococcus aureus [44], suggesting that the risk of infection type might be different between abatacept and TNF inhibitor. It is still necessary to pay attention to bacterial infection to use abatacept.

This study had some limitations. First, it was an observational study, which may have led to selection bias. To balance baseline data, propensity-score matching analysis was performed as a post hoc analysis. However, the number of analyzed patients was small after the propensity-score matching. A large number of cases are needed to obtain a reliable analysis. In younger patients, we could not show the efficacy of abatacept for a EULAR response or changes in DAS28-ESR and SDAI, but abatacept tended to have higher steroid-sparing, after propensity-score matching. The number of matched patients was very small $(n=25)$, and moreover, baseline factors might still not be completely matched. Second, the sample size was small, which might limit the reliability of the findings when applied to additional patient populations. Third, the fact that this study was conducted exclusively in Japan potentially limits its generalizability to other ethnicities. Nevertheless, the findings are important because they illustrate the efficacy of abatacept in older patients with RA.

\section{CONCLUSIONS}

Although the achievement of low disease activity is a goal for both older and younger patients with RA [45], the efficacies of tumor necrosis factor inhibitors and an interleukin- 6 inhibitor were reportedly equal or slightly lower in older patients than in younger patients [46-51]. Furthermore, older patients who use those bDMARDs are at greater risk of serious infections $[19,20]$. In addition to the known benefits of abatacept safety in older patients $[18,21,22]$, our findings indicate that the efficacies of abatacept are similar in older and younger patients with RA. The clinical implication of this prospective study, which concurs with the findings of previous retrospective studies, is that abatacept constitutes an overall more favorable treatment option for older 
patients with RA than adding or switching to a new csDMARD treatment.

\section{ACKNOWLEDGEMENTS}

We wish to thank the participants of the study, members of the ABT-ATS study group, and Mr. Kimihiro Yonezaki for his secretarial assistance. We thank StaGen Co., Ltd. for the statistical analysis.

Funding. This study and the journal's Rapid Service Fee were supported by Bristol-Myers Squibb K.K. and Ono Pharmaceutical Co., Ltd.

Authorship. All named authors meet the International Committee of Medical Journal Editors (ICMJE) criteria for authorship for this article, take responsibility for the integrity of the work as a whole, and have given their approval for this version to be published.

Authorship Contributions. Conceptualization and Methodology: Tamio Teramoto, Toshihiro Nanki; Investigation and Data collection: Sei Muraoka, Zento Yamada, Mai Kawazoe, Hirose Wataru, Hajime Kono, Shinsuke Yasuda, Yukiko Komano, Hiroshi Kawano, Toshihiko Hidaka, Shunsaku Nakashima, Tsuyoshi Kasama, Toshihiro Nanki and ABTATS study group; Analysis: Sei Muraoka, Toshihiro Nanki; Writing-original draft preparation: Sei Muraoka; Writing-review and editing: Toshihiro Nanki; Funding acquisition: Toshihiro Nanki; Supervision: Toshihiro Nanki. All authors read and approved the final manuscript."

Medical Writing Assistance. Medical writing assistance was provided by Ryan ChastainGross, Ph.D., from Edanz Group.

Disclosures. Sei Muraoka has received consultant fees from Asahikasei Pharma Corp., as well as speaker's bureau fees from Ono Pharmaceutical Co., Ltd., Eisai Co., Ltd., Asahikasei Pharma Corp., and Astellas Pharma Inc. Mai Kawazoe received speakers fees Asahikasei Pharma Corp., Mitsubishi-Tanabe Pharma Co.,
Ono Pharmaceutical Co., Ltd., and Chugai Pharmaceutical Co. Hajime Kono received grant/research support from Astellas Pharma Inc., Chugai Pharmaceutical Co., Eisai Co., Ltd., Bristol-Myers K.K., Asahikasei Pharma Corp., Mitsubishi-Tanabe Pharma Co., Ayumi Pharmaceutical Corporation, Nippon Kayaku Co., Ltd. and AbbVie GK, and speakers fees from Chugai Pharmaceutical Co., Eisai Co., Ltd., Astellas Pharma Inc., Janssen Pharmaceutical K.K., Pfizer Japan Inc., Asahikasei Pharma Corp., Eli Lilly Japan K.K., and AbbVie GK. Shinsuke Yasuda received grants and personal fees from AbbVie GK, Asahikasei Pharma Corp, Chugai Pharmaceutical Co., Bristol-Myers K.K./ Ono Pharmaceutical Co., Ltd., Eisai Co., Ltd., Mitsubishi-Tanabe Pharma Co., personal fees from Eli Lilly K.K., GlaxoSmithKline K.K., and Pfizer Japan Inc. Toshihiko Hidaka received speakers fees from AbbVie GK, Asahikasei Pharma Corp., Chugai Pharmaceutical Co., Eli Lilly Japan K.K.,. Bristol-Myers K.K., Mitsubishi-Tanabe Pharma Co., and Eisai Co., Ltd. Tamio Teramoto received grant support from Daiichi Sankyo Co., Ltd. Toshihiro Nanki received grant/research support from Chugai Pharmaceutical Co., Eisai Co., Ltd., Eli Lilly Japan K.K., Bristol-Myers K.K., Ono Pharmaceutical Co., Ltd., Asahikasei Pharma Corp., Mitsubishi-Tanabe Pharma Co., Ayumi Pharmaceutical Corporation, Nippon Kayaku Co., Ltd. and AbbVie GK, consultant fees from UCB Japan Co., Ltd., Eisai Co., Ltd. and Chugai Pharmaceutical Co., and speakers fees from Ono Pharmaceutical Co., Ltd., Chugai Pharmaceutical Co., Eisai Co., Ltd., Astellas Pharma Inc., Janssen Pharmaceutical K.K., Pfizer Japan Inc., Asahikasei Pharma Corp., Eli Lilly Japan K.K., Mylan N.V. and AbbVie GK. The remaining authors declare that they have no conflicts of interest.

Compliance with Ethics Guidelines. The study protocol was approved by the ethics committees of the Faculty of Medicine, Toho University (Approval number: A20114_A17112_A16017_27038), Teikyo University (Approval number: 14-061), and ethics committees of collaborative institutions. This study was performed in accordance with the Helsinki Declaration of 1964 and its later 
amendments. All enrolled patients provided written informed consent to participate.

Data Availability. The datasets generated during and/or analyzed during the current study are available from the corresponding author on reasonable request.

Open Access. This article is licensed under a Creative Commons Attribution-NonCommercial 4.0 International License, which permits any non-commercial use, sharing, adaptation, distribution and reproduction in any medium or format, as long as you give appropriate credit to the original author(s) and the source, provide a link to the Creative Commons licence, and indicate if changes were made. The images or other third party material in this article are included in the article's Creative Commons licence, unless indicated otherwise in a credit line to the material. If material is not included in the article's Creative Commons licence and your intended use is not permitted by statutory regulation or exceeds the permitted use, you will need to obtain permission directly from the copyright holder. To view a copy of this licence, visit http://creativecommons.org/licenses/by$\mathrm{nc} / 4.0 /$.

\section{REFERENCES}

1. McInnes IB, Schett G. The pathogenesis of rheumatoid arthritis. N Engl J Med. 2011;365(23): 2205-19.

2. Grigor C, Capell H, Stirling A, et al. Effect of a treatment strategy of tight control for rheumatoid arthritis (the TICORA study): a single-blind randomised controlled trial. Lancet. 2004;364(9430): 263-9.

3. $\mathrm{Ng} \mathrm{B}$, Chu A, Khan MM. A retrospective cohort study: 10-year trend of disease-modifying antirheumatic drugs and biological agents use in patients with rheumatoid arthritis at Veteran Affairs Medical Centers. BMJ Open. 2013;3(4): e002468.

4. Boots $\mathrm{AMH}$, Maier $\mathrm{AB}$, Stinissen $\mathrm{P}$, et al. The influence of ageing on the development and management of rheumatoid arthritis. Nat Rev Rheumatol. 2013;9(10):604-13.
5. Lenzi J, Avaldi VM, Rucci P, et al. Burden of multimorbidity in relation to age, gender and immigrant status: a cross-sectional study based on administrative data. BMJ Open. 2016;6(12): $\mathrm{e} 012812$.

6. Dougados M, Soubrier M, Antunez A, et al. Prevalence of comorbidities in rheumatoid arthritis and evaluation of their monitoring: results of an international, cross-sectional study (COMORA). Ann Rheum Dis. 2014;73(1):62-8.

7. Michelsen B, Kristianslund EK, Sexton J, et al. Do depression and anxiety reduce the likelihood of remission in rheumatoid arthritis and psoriatic arthritis? Data from the prospective multicentre NOR-DMARD study. Ann Rheum Dis. 2017;76(11): 1906-10.

8. Sugihara T, Ishizaki T, Hosoya T, et al. Structural and functional outcomes of a therapeutic strategy targeting low disease activity in patients with elderly-onset rheumatoid arthritis: a prospective cohort study (CRANE). Rheumatology (Oxford). 2015;54(5):798-807.

9. Murota A, Kaneko Y, Yamaoka K, et al. Safety of biologic agents in elderly patients with rheumatoid arthritis. J Rheumatol. 2016;43(11):1984-8.

10. Strangfeld A, Eveslage $M$, Schneider $M$, et al. Treatment benefit or survival of the fittest: what drives the time-dependent decrease in serious infection rates under TNF inhibition and what does this imply for the individual patient? Ann Rheum Dis. 2011;70(11):1914-20.

11. Salmon JH, Gottenberg JE, Ravaud P, et al. Predictive risk factors of serious infections in patients with rheumatoid arthritis treated with abatacept in common practice: results from the Orencia and Rheumatoid Arthritis (ORA) registry. Ann Rheum Dis. 2016;75(6):1108-13.

12. Wolfe F, Caplan L, Michaud K. Treatment for rheumatoid arthritis and the risk of hospitalization for pneumonia: associations with prednisone, disease-modifying antirheumatic drugs, and anti-tumor necrosis factor therapy. Arthritis Rheum. 2006;54(2):628-34.

13. Caporali R, Caprioli M, Bobbio-Pallavicini F, et al. DMARDS and infections in rheumatoid arthritis. Autoimmun Rev. 2008;8(2):139-43.

14. Bonelli $\mathrm{M}$, Scheinecker C. How does abatacept really work in rheumatoid arthritis? Curr Opin Rheumatol. 2018;30(3):295-300.

15. Schiff M, Weinblatt ME, Valente R, et al. Head-tohead comparison of subcutaneous abatacept versus adalimumab for rheumatoid arthritis: two-year 
efficacy and safety findings from AMPLE trial. Ann Rheum Dis. 2014;73(1):86-94.

16. Kubo S, Nakayamada S, Nakano K, et al. Comparison of the efficacies of abatacept and tocilizumab in patients with rheumatoid arthritis by propensity score matching. Ann Rheum Dis. 2016;75(7): 1321-7.

17. Schiff M, Keiserman M, Codding C, et al. Efficacy and safety of abatacept or infliximab vs. placebo in ATTEST: a phase III, multi-centre, randomised, double-blind, placebo-controlled study in patients with rheumatoid arthritis and an inadequate response to methotrexate. Ann Rheum Dis. 2008;67(8):1096-103.

18. Harigai $M$, Ishiguro $N$, Inokuma $S$, et al. Safety and effectiveness of abatacept in Japanese non-elderly and elderly patients with rheumatoid arthritis in an all-cases post-marketing surveillance. Mod Rheumatol. 2019;29(5):747-55.

19. Koike T, Harigai M, Inokuma S, et al. Effectiveness and safety of tocilizumab: postmarketing surveillance of 7901 patients with rheumatoid arthritis in Japan. J Rheumatol. 2014;41(1):15-23.

20. Komano Y, Tanaka M, Nanki T, et al. Incidence and risk factors for serious infection in patients with rheumatoid arthritis treated with tumor necrosis factor inhibitors: a report from the Registry of Japanese Rheumatoid Arthritis Patients for Longterm Safety. J Rheumatol. 2011;38(7):1258-64.

21. Yun H, Xie F, Delzell E, et al. Comparative risk of hospitalized infection associated with biologic agents in rheumatoid arthritis patients enrolled in Medicare. Arthritis Rheumatol. 2016;68(1):56-66.

22. Ozen G, Pedro S, Schumacher R, et al. Safety of abatacept compared with other biologic and conventional synthetic disease-modifying antirheumatic drugs in patients with rheumatoid arthritis: data from an observational study. Arthritis Res Ther. 2019;21(1):141.

23. Ebina K, Hashimoto M, Yamamoto W, et al. Drug tolerability and reasons for discontinuation of seven biologics in 4466 treatment courses of rheumatoid arthritis - the ANSWER cohort study. Arthritis Res Ther. 2019;21(1):91.

24. Takabayashi K, Ando F, Suzuki T. Comparing the effectiveness of biological disease-modifying antirheumatic drugs using real-world data. Mod Rheumatol. 2019;29(1):87-97.

25. Soubrier M, Lahaye C, Tatar Z. Abatacept for treatment of rheumatoid arthritis: special focus on the elderly. Drugs Aging. 2018;35(5):379-87.
26. Kikuchi H, Shimada W, Mihira S, et al. Selection of abatacept for patients with rheumatoid arthritis aged 70 years or older. EC Orthop. 2019;10(8): 613-6.

27. Aletaha D, Neogi T, Silman AJ, et al. 2010 Rheumatoid arthritis classification criteria: an American College of Rheumatology/European League Against Rheumatism collaborative initiative. Arthritis Rheum. 2010;62(9):2569-81.

28. Bristol-Myers Squibb. ORENICA (abatacept) [package insert]. U.S. Food and Drug Administration website. https://www.accessdata.fda.gov/ drugsatfda_docs/label/2013/125118s171lbl.pdf. 2013. Accessed 18 March 2021

29. Gottenberg JE, Ravaud P, Cantagrel A, et al. Positivity for anti-cyclic citrullinated peptide is associated with a better response to abatacept: data from the 'Orencia and Rheumatoid Arthritis' registry. Ann Rheum Dis. 2012;71(11):1815-9.

30. Mochizuki T, Yano K, Ikari K, et al. The efficacy of abatacept in Japanese patients with rheumatoid arthritis: 104 weeks radiographic and clinical results in clinical practice. Mod Rheumatol. 2016;26(4): 499-506.

31. Nash P, Nayiager S, Genovese MC, et al. Immunogenicity, safety, and efficacy of abatacept administered subcutaneously with or without background methotrexate in patients with rheumatoid arthritis: results from a phase III, international, multicenter, parallel-arm, open-label study. Arthritis Care Res (Hoboken). 2013;65(5):718-28.

32. Takahashi N, Kojima T, Kida D, et al. Concomitant methotrexate has little effect on clinical outcomes of abatacept in rheumatoid arthritis: a propensity score matching analysis. Clin Rheumatol. 2019;38(9):2451-9.

33. Ogawa $\mathrm{N}$, Ohashi $\mathrm{H}$, Ota $\mathrm{Y}$, et al. Multicenter, observational clinical study of abatacept in Japanese patients with rheumatoid arthritis. Immunol Med. 2019;42(1):29-38.

34. Emery P, Burmester GR, Bykerk VP, et al. Evaluating drug-free remission with abatacept in early rheumatoid arthritis: results from the phase $3 \mathrm{~b}$, multicentre, randomised, active-controlled AVERT study of 24 months, with a 12-month, double-blind treatment period. Ann Rheum Dis. 2015;74(1): 19-26.

35. Harigai $M$, Ishiguro N, Inokuma $S$, et al. Postmarketing surveillance of the safety and effectiveness of abatacept in Japanese patients with rheumatoid arthritis. Mod Rheumatol. 2016;26(4):491-8. 
36. Takahashi N, Kojima T, Kaneko A, et al. Longterm efficacy and safety of abatacept in patients with rheumatoid arthritis treated in routine clinical practice: effect of concomitant methotrexate after 24 weeks. J Rheumatol. 2015;42(5):786-93.

37. Westhovens R, Robles M, Ximenes AC, et al. Clinical efficacy and safety of abatacept in methotrexate-naive patients with early rheumatoid arthritis and poor prognostic factors. Ann Rheum Dis. 2009;68(12):1870-7.

38. Kremer JM, Genant HK, Moreland LW, et al. Effects of abatacept in patients with methotrexate-resistant active rheumatoid arthritis: a randomized trial. Ann Intern Med. 2006;144(12):865-76.

39. Genovese MC, Becker JC, Schiff M, et al. Abatacept for rheumatoid arthritis refractory to tumor necrosis factor alpha inhibition. $\mathrm{N}$ Engl $\mathrm{J}$ Med. 2005;353(11):1114-23.

40. Takahashi N, Kojima T, Kida D, et al. Clinical effectiveness and long-term retention of abatacept in elderly rheumatoid arthritis patients: results from a multicenter registry system. Mod Rheumatol. $2019 ; 29(6): 910-8$.

41. Lahaye C, Soubrier M, Mulliez A, et al. Effectiveness and safety of abatacept in elderly patients with rheumatoid arthritis enrolled in the French Society of Rheumatology's ORA registry. Rheumatology (Oxford). 2016;55(5):874-82.

42. Sekiguchi M, Fujii T, Matsui K, et al. Differences in predictive factors for sustained clinical remission with abatacept between younger and elderly patients with biologic-naive rheumatoid arthritis: results from the ABROAD study. J Rheumatol. 2016;43(11):1974-83.

43. Tokunaga K, Matsui K, Oshikawa H, et al. Risk of serious infection, malignancy, or death in Japanese rheumatoid arthritis patients treated with a combination of abatacept and tacrolimus: a retrospective cohort study. Clin Rheumatol. 2020;40(5): 1811-7.
44. Ali A, Welin A, Schwarze JC, et al. CTLA4 immunoglobulin but not anti-tumor necrosis factor therapy promotes staphylococcal septic arthritis in mice. J Infect Dis. 2015;212(8):1308-16.

45. Smolen JS, Landewé RBM, Bijlsma JWJ, et al. EULAR recommendations for the management of rheumatoid arthritis with synthetic and biological disease-modifying antirheumatic drugs: 2019 update. Ann Rheum Dis. 2020;79(6):685-99.

46. Bathon JM, Fleischmann RM, Van der Heijde D, et al. Safety and efficacy of etanercept treatment in elderly subjects with rheumatoid arthritis. J Rheumatol. 2006;33(2):234-43.

47. Hyrich KL, Watson KD, Silman AJ, et al. Predictors of response to anti-TNF-alpha therapy among patients with rheumatoid arthritis: results from the British Society for Rheumatology Biologics Register. Rheumatology (Oxford). 2006;45(12):1558-65.

48. Radovits BJ, Kievit W, Fransen J, et al. Influence of age on the outcome of antitumour necrosis factor alpha therapy in rheumatoid arthritis. Ann Rheum Dis. 2009;68(9):1470-3.

49. Hetland ML, Christensen IJ, Tarp U, et al. Direct comparison of treatment responses, remission rates, and drug adherence in patients with rheumatoid arthritis treated with adalimumab, etanercept, or infliximab: results from eight years of surveillance of clinical practice in the nationwide Danish DANBIO registry. Arthritis Rheum. 2010;62(1): 22-32.

50. Pers YM, Schaub R, Constant E, et al. Efficacy and safety of tocilizumab in elderly patients with rheumatoid arthritis. Jt Bone Spine. 2015;82(1): 25-30.

51. Köller MD, Aletaha D, Funovits J, et al. Response of elderly patients with rheumatoid arthritis to methotrexate or TNF inhibitors compared with younger patients. Rheumatology (Oxford). 2009;48(12):1575-80. 